ANALITIKA

Available online http://ojs.uma.ac.id/index.php/ analitika

\title{
Peran Kompetensi Sosial Terhadap Coping Stress Pada Remaja
}

\section{The Role of Social Competence Against Coping Stress In Teens}

\author{
Juli Maini Sitepu
}

Universitas Muhammadiyah Sumatera Utara, Indonesia

*Corresponding author: E-mail: syafiqah2011@yahoo.co.id

\begin{abstract}
Abstrak
Penelitian ini dilakukan untuk melihat bagaimana peran kompetensi sosial terhadap coping stress pada remaja. Populasi dalam penelitian ini adalah siswa-siswi SMP Harapan 2 Medan, Sumatera Utara dengan subjek yang digunakan berjumlah 150 orang yang terdiri dari siswa dan siswi. Adapun hipotesis yang diajukan dalam penelitian ini adalah kompetensi sosial memiliki pengaruh positif terhadap coping stress. Untuk mengumpulkan data dalam penelitian ini menggunakan skala yaitu skala kompetensi sosial dan skala coping stress sebagai alat pengumpulan data. Pada skala ini subjek diminta untuk memilih salah satu dari empat alternatif jawaban yang sudah tersedia. Setelah pengumpulan data dilakukan, maka selanjutnya adalah melakukan analisis data. Analisis data dilakukan dengan menggunakan program SPSS versi 15,0 dan untuk menguji hipotesis menggunakan uji T. Hasil penelitian membuktikan bahwa hipotesis dengan pernyataan kompetensi sosial berperan positif terhadap coping stres adalah ditolak. Hal ini ditunjukkan dengan nilai $\mathrm{F}=1,081$ dengan tingkat probabilitas tidak signifikan $\mathrm{p}=0,3(\mathrm{p}>0,05)$ sehingga hasil membuktikan bahwasanya kompetensi sosial berperan negatif terhadap coping stres pada remaja. Hal ini membuktikan bahwasaya ada faktorfaktor lain dalam pembentukan kompetensi sosial remaja yang nantinya dapat mempengaruhinya dalam membuat strategi coping yang tepat dalam mengatasi stres.
\end{abstract}

Kata Kunci: Kompetensi Sosial, Coping Stress, Remaja

\begin{abstract}
This study was conducted to see how the role of social competence to coping stress in adolescents. The population in this study were students of SMP Harapan 2 Medan, North Sumatera with the subject used 150 students consisting of students and girls. The hypothesis proposed in this study is that social competence has a positive effect on coping stress. To collect data in this study using the scale of social competence scale and scale coping stress as a means of data collection. On this scale the subject is asked to choose one of four alternative answers that are already available. After data collection is done, then next is to do data analysis. Data analysis was done by using SPSS program version 15.0 and to test hypothesis using $T$ test.

The results of this study prove that hypothesis with the statement of social competence positively to coping stress is rejected. This is indicated by the value of $F=1,081$ with the level of probability is not significant $p$ $=0.3(p>0.05)$ so that the results prove that social competence play a negative role to coping stress in adolescents. This proves that there are other factors in the formation of adolescent social competence that later can influence it in making appropriate coping strategies in dealing with stress.
\end{abstract}

Keywords: Social Competence, Coping Stress, Youth

How to Cite: Sitepu, J. M., (2017), Peran Kompetensi Sosial Terhadap Coping Stress Pada Remaja, ANALITIKA, Vol 9 (2): 85 - 90 


\section{PENDAHULUAN}

Masa remaja merupakan periode yang sangat rawan, dimana pada masa ini, banyak permasalahan yang tengah dihadapi oleh para remaja, baik masalah dengan dirinya sendiri, dengan orangtua, keluarga, maupun masalah dengan teman sebaya dan lingkungan, jika permasalahan-permasalahan tersebut tidak dapat diatasi oleh para remaja maka akan dapat menimbulkan stres bagi remaja. Tidak semua remaja mampu mengatasi stresnya dengan baik. Ada remaja yang mengatasinya dengan melakukan hal-hal yang negatif seperti kenakalan remaja

Remaja sangat ingin kehadirannya diterima oleh orang-orang yang ada dalam lingkungannya, baik dirumah, di sekolah maupun dalam masyarakat dimana ia tinggal. Rasa diterima kehadirannya oleh semua pihak ini menyebabkan remaja merasa aman dan nyaman karena ia merasa bahwa ada dukungan dan perhatian terhadap dirinya. Lingkungan sosial yang paling mempengaruhi remaja adalah teman sebaya terutama di sekolah, remaja lebih banyak berada di luar rumah bersama teman-teman sebaya sebagai kelompok dan hal ini yang sering mendatangkan permasalahan pada remaja itu sendiri. Pada lingkungan sosial, remaja juga mengalami tekanan teman sebaya dan tuntutan konformitas yang menuntut mereka untuk menjadi sama dengan teman-teman sebayanya agar dapat diterima (Santrock, 2003). Kesulitan remaja dalam menyesuaikan diri dengan lingkungan sosialnya disebabkan adanya kompetensi sosial yang remaja miliki, sebab kesuksesan dalam penyesuain sosial dibutuhkan kompetensi sosial yang baik
(Welsh dan Bierman, 1998). Durkin (1995) mengatakan bahwa kompetensi sosial merupakan suatu komponen yang utuh dari sebuah persahabatan, sehingga jika dalam hubungan sosial tidak mampu menghargai adanya persahabatan maka hal ini akan menimbulkan permasalahan. Hurlock (1994) juga menambahkan semakin banyak partisipasi sosial, semakin besar kompetensi sosial remaja. Semakin besar kompetensi sosial memiliki peranan yang sangat penting dalam kehidupan remaja baik pada masa sekarang maupun untuk masa yang akan datang, dan juga sangat penting bagi masyarakat secara keseluruhan. Dalam setiap kehidupan, individu akan selalu membutuhkan kehadiran orang lain baik dalam hubungan interpersonal maupun hubungan kelompok. Keberhasilan seseorang dalam kehidupan bermasayarakat dibutuhkan adanya kompetensi sosial yang tinggi, sebab kualifikasi seseorang (human capital) yang bagus tanpa dibarengi dengan adanya kemampuan dalam berhubungan sosial (social capital) dapat menghambat keberhasilannya (Rejeki, 2005). Menurut Welsh dan Bierman (1998) individu yang memiliki kompetensi sosial tinggi adalah mereka yang memiliki sikap dan perilaku yang lebih banyak positif dan sedikit negatif dalam menerima orang lain

Sekolah sebagai tempat siswa menghabiskan banyak waktunya dan sebagai tempat mereka belajar diharapkan dapat memberikan sesuatu yang berharga berupa pengetahuan, pengalaman dan lingkungan sosial yang baik agar mereka dapat menyesuaikan diri dalam lingkungan masyarakat yang lebih besar. Berbagai permasalahan yang terjadi yang 
dilakukan remaja sehingga menimbulkan keresahan oleh berbagai pihak, baik masyarakat, sekolah, orangtua maupun pemerintah disebabkan oleh minimnya pengetahuan remaja tentang bagaimana cara mengatasi masalahnya sehingga masalah tersebut tidak terselesaikan dan menimbulkan stres pada diri remaja, dan untuk mengatasi perasaan stres itu remaja mengaplikasikannya dalam bentuk kenakalan. Sekarang ini kenakalan remaja sudah semakin banyak, bukan hanya diluaran, para remaja juga sudah mulai berani melakukan tindakan-tindakan negative di sekolah seperti membuly teman-teman, beratem di sekolah, pelecehan seksual disekolah, melawan guru di sekolah. Semua kenakalankenakalan tersebut adalah bentuk dari ketidakmampuan para remaja untuk mengatasi permasalahan di dalam kehidupannya, terutama masalah-masalah sosial.

\section{METODE PENELITIAN}

Pada penelitian ini subjek yang digunakan adalah siswa di SMP Harapan 2 Medan yang duduk di kelas IX (III SMP) yang berjumlah 150 orang yang terdiri dari siswa perempuan 72 orang dan siswa laki-laki 78 orang. Alasan memilih subjek tersebut dikarenakan siswa SMP masuk pada tahap remaja awal, dimana pada masa remaja awal merupakan masa periode yang penting yang banyak membawa konsekuensi baik sikap maupun perilaku. Remaja mengalami peralihan dan perubahan yang akan membawa dampak dalam kehidupannya di masa yang akan datang.

Skala yang digunakan dalam penelitian ini adalah skala coping stres, yang disusun sendiri oleh peneliti berdasarkan aspek-aspek yang diungkapkan oleh para ahli. Skala coping stres disusun berdasarkan strategi coping yang dikemukakan Lazarus Folkman (dalam Sarafino, 1997) yakni emotion focused coping yang terdiri dari lima komponen yaitu distancing, escape avoidance, self controlling, accepting responsibility, positive reappraisal dan problem focused coping yang dibedakan dalam tiga kelompok, yakni, planful problem solving, confrontative coping, dan seeking social support. Adapun jumlah butir item dalam skala coping stres berjumlah 41 butir pernyataan. Pada skala ini subjek diminta untuk memilih salah satu dari empat alternatif jawaban. Penyusunan aitem dikelompokkan dalam bentuk favorable dan unfavorable. Pemberian skor untuk butir favourable adalah 4 sampai 1, sedangkan untuk butir yang unfavorable adalah 1 sampai 4 . Ketentuan skor 4 untuk jawaban yang sangat setuju (SS), skor 3 untuk jawaban setuju (S), skor 2 untuk jawaban tidak setuju (TS), dan skor 1 untuk jawaban sangat tidak setuju (STS). Sementara untuk butir unfavorable skor 1 diberikan untuk jawaban sangat setuju (SS), skor 2 untuk jawaban setuju (S), skor 3 untuk jawaban tidak setuju (TS), dan skor 4 untuk jawaban sangat tidak setuju (STS).

Skala kedua yang digunakan adalah skala kompetensi sosial yang disusun berdasarkan aspek-aspek kompetensi sosial berjumlah 35 butir pernyataan yang dikemukakan oleh Welsh \& Bierman (1998) bahwa kompetensi sosial tergantung pada kemampuan kognisi, emosi, dan sosial, yang dapat diuraikan melalui tiga aspek yaitu kognisi sosial 
(Social cognition), kecerdasan emosi (emotional intelligence) dan keterampilan sosial (social skill). Adapun jumlah butir pernyataan untuk mengungkap kompetensi sosial siswa sebanyak 37 butir pernyataan.Pada skala ini subjek diminta untuk memilih salah satu dari empat alternatif jawaban. Penyusunan aitem dikelompokkan dalam bentuk favorable dan unfavorable. Pemberian skor untuk butir favorable adalah 4 sampai 1 , sedangkan untuk butir yang unfavorable adalah 1 sampai 4 . Ketentuan skor 4 untuk jawaban yang sangat setuju (SS), skor 3 untuk jawaban setuju (S), skor 2 untuk jawaban tidak setuju (TS), dan skor 1 untuk jawaban sangat tidak setuju (STS). Sementara untuk butir unfavorable skor 1 diberikan untuk jawaban sangat setuju (SS), skor 2 untuk jawaban setuju (S), skor 3 untuk jawaban tidak setuju (TS), dan skor 4 untuk jawaban sangat tidak setuju (STS). Sebelum alat ukur benar-benar diberikan pada subjek penelitian, maka sebelumnya diadakan try out ( uji coba) terlebih dahulu agar alat ukur yang akan digunakan benar-benar valid dan reliabel. Metode analisis data yang digunakan untuk menguji hipotesis dalam penelitian ini menggunakan uji $\mathrm{T}$ dengan menggunakan program Statistical for Social Science (SPSS) for Windows versi 15.

\section{HASIL DAN PEMBAHASAN}

Skala coping stres terdiri dari 41 butir pernyataan yang terbagi dalam delapan aspek. Hasil estimasi validitas skala coping stres menunjukkan bahwa terdapat delapan butir yang gugur $(\mathrm{r}<$ 0,25 ) yaitu butir $10,18,25,26,32,33,39,41$ sehingga jumlah pernyataan yang sahih ada 33 butir dengan rentang koefisien korelasi aitem-total bergerak antara 0,254-0,475 selanjutnya terhadap 33 butir yang sahih tersebut dilakukan estimasi reliabilitas dan menghasilkan koefisien Alpha Cronbach sebesar 0,859 dan dapat dikatakan reliable.

Skala kompetensi sosial terdiri dari 35 butir pernyataan yang terbagi dalam tiga aspek. Hasil estimasi validitas skala kompetensi sosial menunjukkan bahwa terdapat tiga butir yang gugur $(\mathrm{r}<0,25)$ yaitu butir 10,16,18 sehingga jumlah pernyataan yang sahih ada 32 butir dengan rentang koefisien validitas bergerak antara 0,264-0,645, selanjutnya terhadap 32 butir yang sahih tersebut dilakukan estimasi reliabilitas dan menghasilkan koefisien Alpha Cronbach sebesar 0,879 dan dapat dikatakan reliabel.

Hasil penelitian membuktikan bahwa kompetensi sosial berperan positif terhadap coping stres adalah ditolak. Hal ini ditunjukkan dengan nilai $\mathrm{F}=1,081$ dengan tingkat probabilitas tidak signifikan $p=0,3(p>0,05)$ sehingga hasil membuktikan bahwasanya kompetensi sosial berperan negatif terhadap coping stres siswa. Hal ini membuktikan ada faktor-faktor lain dalam pembentukan kompetensi sosial remaja yang nantinya dapat mempengaruhinya dalam membuat strategi coping yang tepat dalam mengatasi stres. Kompetensi sosial merupakan salah satu faktor yang dapat mempengaruhi strategi coping yang akan dibuat oleh remaja, akan tetapi hal ini bukan menjadi faktor yang dominan terhadap coping stres pada subjek, masih banyak faktor lain yang lebih dominan terhadap strategi coping yang akan dibuat, 
misalnya jenis kelamin, pengalaman dan keluarga.

Terdapat perbedaan kompetensi sosial antara laki-laki dan perempuan, dimana anak laki-laki menunjukkan lebih banyak masalah sosial bila dibandingkan anak perempuan pada keluarga dengan status sosial ekonomi rendah (Torres, M.V.T, et al., 2003) dan terdapat perbedaan cara dalam menyelesaikan masalah antara laki-laki dan perempuan. Seperti yang diungkapkan oleh Billings dan Moos (1984) bahwa wanita lebih cenderung menggunakan coping yang berfokus pada emosi dalam menghadapi masalah, sedangkan laki-laki sering menggunakan coping yang berfokus pada masalah. Hal ini menunjukkan bahwa jenis kelamin menjadi faktor yang dapat menentukan coping stres.

Pengalaman seseorang juga berperan dalam membentuk strategi coping yang akan dibuat. Semakin banyak pengalaman hidup seseorang maka semakin banyak alternatif yang akan digunakan dalam mengatasi masalah. Atkinson dan Hilgrad (1999) menyebutkan bahwa para ahli lebih banyak mempunyai konfigurasi yang dapat digunakan dalam memecahkan masalah. Masa remaja yang merupakan peralihan dari masa anak-anak dan masih mencari jati diri belum memiliki pengalamn hidup yang cukup untuk membuat suatu strategi coping yang tepat. Hal ini dikarenakan remaja masih mengandalkan ego-nya dalam mengatasi permasalahannya, dan remaja masih belajar untuk dapat hidup mandiri dalam mengatasi permasalahannya, sebab pada saat anak-anak permasalahan yang terjadi kebanyakan diselesaikan oleh orangtua atau orang yang lebih dewasa sehingga remaja belum memiliki pengalaman untuk mengatasi masalahnya sendiri.

Kebutuhan remaja untuk diakui dan dapat diterima dalam kelompok teman sebayanya dapat mengurangi sedikit permasalahan yang dapat menghindarkannya dari stres, akan tetapi kemampuan sosialisasi remaja tersebut tidak serta merta terjadi begitu saja. Ada peran keluarga yang membantu seorang remaja dapat beradaptasi dengan lingkungannya. Sarwono mengatakan bahwa keluarga merupakan lingkungan primer pada setiap individu. Sebelum seorang anak mengenal lingkungan yang luas, ia terlebih dahulu mengenal lingkungan keluarganya, oleh karena itu sebelum seorang anak mengenal norma-norma dan nilai-nilai dari masayarakat, pertamakali anak akan menyerap norma-norma dan nilai-nilai yang berlaku dalam keluarganya untuk dijadikan bagian dari kepribadiannya. Dalam keluarga peran kelekatan sangat penting bagi pertumbuhan seorang anak terutama peran kelekatan seorang ibu.

Kelekatan antara ibu dan anak dapat membentuk pribadi yang positif bagi seorang anak yang nantinya akan dibawanya hingga anak tumbuh menjadi remaja dan dewasa. Hal ini sesuai dengan pendapat Bowlby (dalam Rohanna, 2010) bahwa kelekatan antara anak dengan ibu atau yang mengasuhnya merupakan landasan penting bagi perkembangan sosial dan emosional anak dalam kehidupannya di masa yang akan datang. Remaja yang memiliki kelekatan dengan ibu akan membentuk pribadi yang positif dan akan memiliki keterampilanketerampilan yang akan membuatnya 
bertahan dalam lingkungan sosialnya, sehingga remaja tersebut tidak mudah putus asa dalam mengatasi permasalahan yang terjadi dalam hidupnya dan remaja akan mampu membuat coping yang tepat dalam mengatasi permasalahannya sehingga ia dapat terhindar dari stres.

\section{SIMPULAN}

Berdasarkan hasil penelitian dan pembahasan yang telah diuraikan sebelumnya, maka dapat diambil kesimpulan Kompetensi sosial berperan negatif terhadap coping stres. Hal ini menunjukkan bahwa kompetensi sosial bukan faktor yang dominan terhadap coping stres yang akan dibuat siswa. Terdapat perbedaan kompetensi sosial antara laki-laki dan perempuan, dimana anak laki-laki menunjukkan lebih banyak masalah sosial bila dibandingkan anak perempuan pada keluarga dengan status sosial ekonomi rendah (Torres, M.V.T, et al., 2003) dan terdapat perbedaan cara dalam menyelesaikan masalah antara lakilaki dan perempuan. Seperti yang diungkapkan oleh Billings dan Moos (1984) bahwa wanita lebih cenderung menggunakan coping yang berfokus pada emosi dalam menghadapi masalah, sedangkan laki-laki sering menggunakan coping yang berfokus pada masalah. Hal ini menunjukkan bahwa jenis kelamin menjadi faktor yang dapat menentukan coping stres.

Pengalaman seseorang juga berperan dalam membentuk strategi coping yang akan dibuat. Semakin banyak pengalaman hidup seseorang maka semakin banyak alternatif yang akan digunakan dalam mengatasi masalah.

\section{DAFTAR PUSTAKA}

Durkin, K. (1995). Developmental social psychology. Massachusetts: Blackwell Publisher Inc..

Hurlock, E. B. (1994). Psikologi perkembangan: Suatu pendekatan sepanjang rentang kehidupan. Terjemahan. Penerbit Erlangga.

Marini, L, Khairiah M.R, (2015), Perbedaan Kompetensi Komunikasi antara Remaja yang Menggunakan Dua Bahasa (Bilingual) dan Satu Bahasa (Monolingual), Analitika: 7 (2): $58-66$

Mőnks, F.J., Kroners, A.M.P. \& Haditono, S.R. (1999). Psikologi perkembangan: Pengantar dalam berbagai bagiannya. Yogyakarta: Gadjah Mada University Press.

Rejeki, S. (2005). Kompetensi sosial ditinjau dari harga diri dan religiusitas pada siswa program akselerasi dan siswa program reguler. Tesis (tidak diterbitkan). Yogyakarta: Fakultas Psikologi Universitas Gadjah Mada.

Rohanna, R. (2010). Kompetensi sosial anak ditinjau dari kelekatan aman dan jenis kelamin. Tesis (tidak diterbitkan). Yogyakarta: Fakultas Psikologi Universitas Gadjah Mada.

Santrock, J.W. (2003). Adolescence: Perkembangan remaja. Terjemahan Adelar \& Saragih. Jakarta: Erlangga.

Sarafino, E.P. (1998). Health psychology: Biopsychosocial intervention. Third Edition. New York: John Willey \& Sons, Inc.

Syarifah, Nefi D., (2010), Pengaruh Locus Of Control dan Kecerdasan Emosional terhadap Kemampuan Memecahkan Masalah pada Remaja Desa Percut Kecamatan Percut Sei Tuan, Analitika: 2 (2): 88-98

Torres, M. V. T., Elawar, M. G., Mena, M. J. B \& Sanchez, A. M. M., (2003). Social background, gender and self-reported social competence in 11-and 12- year old andalusian children. Electronic Journal of Research in Educational Psychology. 1(2): 37-56.

Welsh, J.A \& Bierman, K.L. (1998). Social competence. Gale encyclopedia of childhood and adolescence. Diakses dari www.findarticles.com pada bulan Novenber 2009.

Angermeyer, M.C., Breier, P., Dietrich, S., Kenzine, D., \& Matschinger, H. (2005). Public attitudes toward psychiatric 